dilemmas that general practitioners are frequently faced with, it admirably fulfils the task. The discussions of cases are enlightening, and will contribute to raising the quality of debate about ethical issues in general practice.

The book's introduction includes the sentence:

'Family physicians should become accustomed to considering the ethical aspects of their practice as routinely as they consider the biomedical, psychological and social dimensions'.

This book is a worthy contribution to that campaign and should help raise the ethical consciousness of general practitioners.

It deserves to be widely read.

DR SIMON LUNDY Lecturer, Department of General Practice, Guy's Hospital Medical School, London

\section{The Human/Animal Connection}

Randall L Eaton, editor, 90 A4 pages, $\$ 20$, Sierra Nevada College Press and the journal Carnivore: Interfacing

Biology, Anthropology and

Environmental Studies, 1985.

This excellent collection of essays provides the reader with 'something new and something old' in the way we see the other animals that share this planet with us.

Randall Eaton, who edits the work, captures the essence of all the essays in his opening paragraph:

'The threat of global war and the equally dismal ecological problems have one origin: humanity . . .

... . As the dominant species, every one of our global problems comes back to human greed or selfishness, soluble only by greater co-operation'.

In discussing how man came to be the most competitively successful species that ever lived, Dr Eaton discusses one or two novel hypotheses. For example, that virtually the whole of human culture owes its existence to 'man the hunter'. Thus early man's imitation of the animal to deceive it when being hunted provided us with the faculties by which we make and transmit culture. Weapons were among the first musical instruments and song originates, not only from imitating animal sounds, but from using voice to announce one's presence in advance. Dance, drama and mime also have a common origin in the imitation of animals' movements.

Gary Snyder, in his essay, 'Poetry and the Magic of Animals', comments on the 'wildness' of animals:

'A relationship with an animal that has been domesticated is very different from meeting with a being that is a complete subject, fully free, selfmanaging, self-complete, self-aware'.

Charles Cameron, a poet rather than a scientist, takes us back in time to retell the stories of the North American Redman, that great family of many tribes who were at one with all living forces and who knew and accepted the oneness of all life.

Dr Michael Fox, a veterinarian and good friend, in his Duty and the Beast, also makes reference to the Redman in writin; of the present plight of the animal kingdom, which is a symptom of what the Hopi Indians called 'Koyaanasquatsi', or 'life out of balance'. In discussing what we are doing to our environment and what we do to animals, he refers to the growing world-wide animal welfare and animal rights movement which, he says, is:

'A revolutionary force that uses reason and emotion - love (as respect for the sanctity and dignity of all life) - to bring about the peaceful transformation of society'.

Dr Fox also echoes the Indian view that all things on earth are related. The choice, he says, for man, between extinction and continuation, between suicide and adoration, rests and depends upon our acceptance of the fact that all life is one family.

Dr Paul Shepard takes the reader along a path of philosophical thought on the agony of our planet.

Dr Eaton, a scientist, as are most of the contributors, takes a view which perhaps sums up the ethos of this most interesting and worthwhile study by quoting Konrad Lorenz:

'To understand an animal, one must first love it. To a non-scientist such a declaration might not deserve more than casual notice, but for a scientist to tell other scientists that love is an essential ingredient for understanding an animal or anything else for that matter is to commit the sin of subjectivism'.

To which Dr Eaton adds:

'Certainly this great myth of Western man we call science does not permit love, if for no other reason than the fact that it is immeasurable'.

My only criticisms of this book are that A4 size is not the most convenient and the style of presentation, with most pages being in two columns, was, I found, awkward. The inserted quotes from many sources through the ages add considerably to the interest of this fascinating book.

CLIVE HOLLANDS Director,

Scottish Society for the Prevention of Vivisection, Edinburgh

\section{Health, the Politician's Dilemma}

George Teeling Smith, 22 pages, London, $£ 1.00$, Office of Health Economics, 1986.

This paperback outlines, in a few pages, the difficulties of meeting demands in the National Health Service in a climate of resource shortage but steady advance in medical care. The United Kingdom has tumbled down the world rankings for health expenditure per head of population and as a percentage of gross national product, hospital waiting lists have escalated and treatment rates fall short of those performed by our European neighbours.

Several of the contributors to today's widening discrepancy between health service demand and resource are inadequately discussed. The dilemma is self-perpetuating. As doctors become more successful at both preventing and treating disease, we live longer and our opportunities for expending health resources are extended. Improvements in education, together with changing attitudes have increased the $N$ expectations of the public, which further fuels demand.

Three approaches to improving the $\mathrm{W}$ level of services which do not $\sigma$ necessitate a corresponding increase in resource are proposed: improved efficiency by the creation of an 'internal $\mathscr{Q}$ market' within the National Health Service; the allocation of available resource to 'maximum utility' for the population; and the attraction of alternative funds, whether they be from private sources or medical charities. Teeling Smith heralds these solutions as 'new ideas', but they are, in fact very familiar. With regard to tightening-up efficiency, the author does not discuss 